\title{
Testing a steam-formaldehyde sterilizer for gas penetration efficiency
}

\author{
STUART J. LINE ${ }^{1}$ AND J. K. PICKERILL \\ From the Department of Microbiology, Northwick Park Hospital, Harrow, and British Sterilizer Co Ltd, \\ Hainault, Essex
}

SYNOPSIS A test piece is described for monitoring the performance of low-temperature steam-with $\frac{\Omega}{\sqrt{3}}$ formaldehyde sterilizers. Comparative tests have shown it to be more difficult to penetrate than an arterial catheter when exposed to the same sterilizing conditions. It is permanent and simple to useु and maintain. The growth or non-growth of bacterial spores, in the convenient form of spore strips; is used to indicate the efficacy of sterilization.

There is a growing interest in low-temperature steam-with-formaldehyde for sterilizing heat-sensitive materials. Many plastic articles and optical surgical instruments cannot withstand high-pressure steam but are unharmed by exposure to steam and formaldehyde at a temperature of $80^{\circ} \mathrm{C}$. A practical version of this system was described by Alder, Brown, and Gillespie (1966). Although they proposed the system for disinfection rather than for sterilization, the bactericidal and sporicidal properties of steam-formaldehyde have since been demonstrated by Gibson and Johnston (1967), Mitchell and Alder (1970), Alder, Gingell, and Mitchell (1971), and by others.

As in other steam or gas-sterilizing methods, as much air as possible must be removed from the chamber and load before formaldehyde is admitted. Thorough removal of the gas after sterilization is important and a post-sterilization vacuum is therefore necessary. In general, the working conditions of humidity, gas concentration, and time required by formaldehyde are less critical than those for ethylene oxide (Kelsey, 1967). Formaldehyde is often preferred because of its lower cost, inherent freedom from the risk of explosion, and because the amount of formaldehyde remaining in various materials after sterilizing has been shown to be very slight (Gibson and Johnston, 1967; Gibson, Johnston, and Turkington, 1968). An airing-off period after sterilization further reduces the concentration of residual formaldehyde.

Unlike high-temperature-steam sterilization, for

'Present address: Department of Bacteriology Public Health Laboratory, East Birmingham Hospital, Bordesley Green East, Birmingham B9 5ST.

Received for publication 12 June 1973. which there are convenient non-biological efficiencys tests, such as Browne's tubes and the Bowie-Diclo tape test (Bowie, Kelsey, and Thompson, 1963) $\frac{\mathbb{Q}}{3}$ there is no convenient test for a steam-formaldehyde system. Biological tests of various kinds have been devised for assessing the penetrative and sporicidal $\overrightarrow{0}$ effect of steam-formaldehyde but none has yefu gained general acceptance. This lack of a reliable and easily prepared test piece has contributed to thes uncertainties in the minds of some users about the efficacy of their equipment.

The pressure variations that can be expected to occur during a steam-formaldehyde cycle and the ability of the gas to creep through tiny crevices make the provision of gas-tight joints in any artificia 5 test piece something of a problem, especially when if is made of dissimilar materials. A permanent test. piece that can be easily set up at the time of sterilio zing is described here.

\section{Materials and Methods}

STERILIZER

This was a $14 \mathrm{cu} \mathrm{ft}$ (400 litre) sliding door Motoclave made by the British Sterilizer Co Ltd. It combines a․ subatmospheric steam-formaldehyde cycle with an standard high-pressure-steam dressings cycle. The temperature for the formaldehyde cycle can be varied but is normally set for $80^{\circ} \mathrm{C}$. Each cycle is fullyw automatic and is selected by a key-operated switch In about $50 \%$ of the test runs, routine loads wereo included. The staging and pressure characteristicsD of the formaldehyde cycle are shown in figure 1.

FORMALDEHYDE

Analar formaldehyde was used in $37 \% \mathrm{w} / \mathrm{v}$ solution 716 


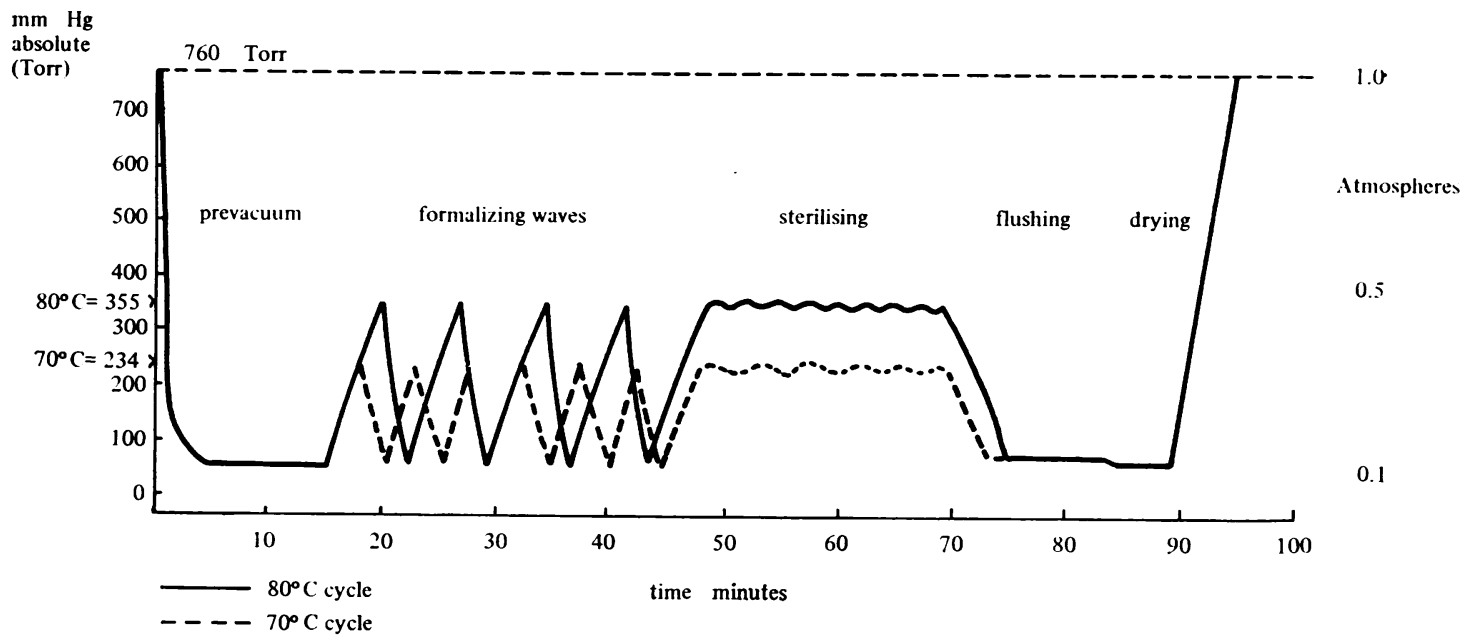

Fig 1 Pressure characteristics of the formaldehyde cycle

(methanol content $11-14 \% \mathrm{w} / \mathrm{w}$ ). During each cycle $200-250 \mathrm{ml}$ of solution was inspired into the machine, the amount depending upon the number of subatmospheric pressure waves during the formalinizing stage.

\section{TEST ORGANISMS}

The sporing indicator organisms were Bacillus stearothermophilus (Oxoid spore strips code BR23), Bacillus pumilis (NCTC 10337), Clostridium sporogenes (NCTC 533), and Bacillus subtilis var. globigii (NCTC 1073). Strains from the National Collection of Type Cultures were used in blotting-paper strips impregnated from liquid suspensions after growth in media to encourage spore formation. Spore counts of $\boldsymbol{B}$. globigii on strips indicated an average of 2.5 $\times 10^{6}$ per strip. After each sterilizing cycle the spore strips from the test pieces and the control strips were cultured in recovery media: cooked-meat medium (Oxoid CM82) for $\mathrm{Cl}$. sporogenes and dextrose-tryptone (Oxoid CM74) or tryptone-soya broth (Oxoid CM130) for the other organisms. Incubation was at $37^{\circ} \mathrm{C}$ for seven days except for $B$. stearothermophilus which was incubated at $56^{\circ} \mathrm{C}$. Because of the high degree of formaldehyde removal in the last two stages of the sterilizing cycle it was not found necessary to use more than $10 \mathrm{ml}$ of recovery medium. All positive results became obvious within two to five days' incubation.

\section{TEST HELIX}

The test piece (fig 2) consisted of stainless steel tubing with a gas-tight brass capsule for the spore strip at one end. The capsule (fig 3) was in two parts,

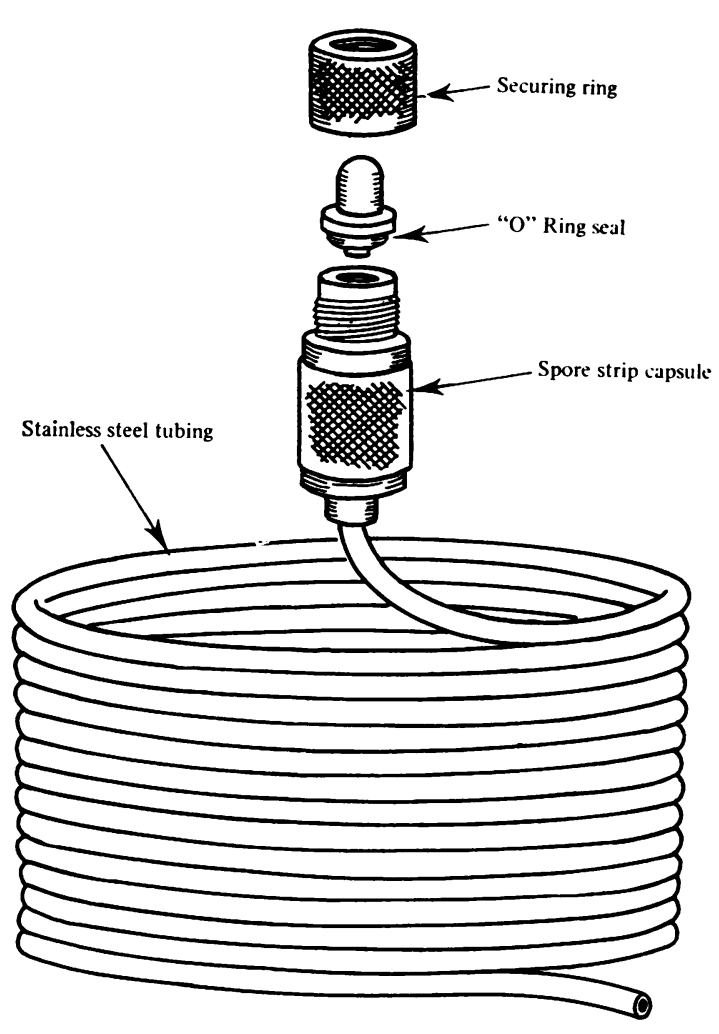

Fig 2 The test helix. Bore/length ratio $=\frac{3 \mathrm{~mm} \text { bore }}{4550 \mathrm{~mm} \text { long }}$

$$
=\frac{1}{1500}
$$




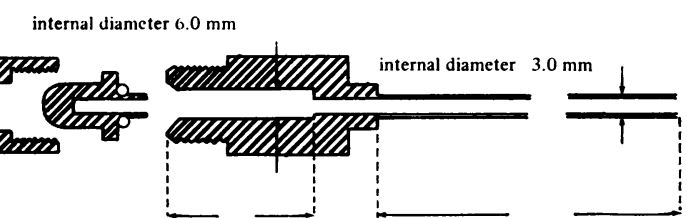

$30 \mathrm{~mm}$

Fig 3 Test helix capsule

which fitted together against an O-ring seal and was secured by a knurled ring. The capsule body was brazed to the stainless steel tube so that the only entry into the assembled capsule was via the whole length of the tube. In the final design the tube was $455 \mathrm{~cm}(15 \mathrm{ft})$ long and the internal diameter was $3.0 \mathrm{~mm}(1 / 8 \mathrm{in}$.) thus presenting a single-ended system with a length-to-bore ratio of $1500: 1$. The total internal volume of the test piece was about 32 $\mathrm{ml}$ of which $0.85 \mathrm{ml}$ comprised the capsule volume. Lengthening the tubing increased the length-bore ratio and made the killing of spores in the capsule more difficult.

For compactness the tube was formed into a helix of about $11.5 \mathrm{~cm}\left(4 \frac{1}{2}\right.$ in.) diameter. Its tail was turned out slightly for ease of connexion to air or water services for cleaning. With the sterilizing system used, simple air-rinsing of the test piece after each cycle sufficed for cleaning; with the head of the capsule removed, the tail of the helix was connected by rubber tubing to a water-venturi suction pump

and air was drawn through it for several minutes. Difficulties due to the deposition of the solid $\underline{\underline{O}}$

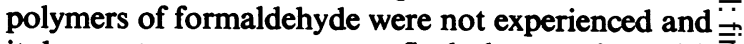
it does not seem necessary to flush the test piece with $\stackrel{\vec{\rho}}{9}$ water.

\section{USE OF THE TEST HELIX}

The capsule was loaded with a spore strip and firmly $\stackrel{\varnothing}{\varrho}$ sealed by the securing ring. In our tests the helix was packed in a paper bag which was then sealed with $\vec{\circ}$ autoclave tape but this is not necessary for routine use. It was placed, capsule uppermost, in the cham- $\vec{\omega}$ ber of the sterilizer and the cycle started. Placing the $?$ helix on its side or even upside down did not affect $\frac{0}{0}$ its performance significantly. The test piece may be $\tilde{N}$ included with other materials in routine runs or used 0 on its own.

After the sterilizing cycle the load and the helix were $\vec{\sigma}$ examined for dryness and the load was stored until 음 bacteriological tests were completed. The spore strip $\vec{c}$ was aseptically removed and put in $10 \mathrm{ml}$ of recovery $\Phi$ medium. The positive control was a spore strip $\frac{\vec{D}}{\mathrm{D}}$ inside an identical capsule with a sealed end replacing $\frac{\mathbb{}}{3}$ the stainless steel tubing. Culture of the spores from $\Phi$ the control capsule always showed growth, indicating $\overrightarrow{-}$ that the temperature of the sterilizing process was ngt 9 itself sufficient to kill them and that the capsule and seal remained gas-tight after frequent use for at leasit six months. In all tests a spore strip or strips in small glassine envelope was put in the paper bag containing the test helix. These strips, which always showed no growth, provided the negative controls.

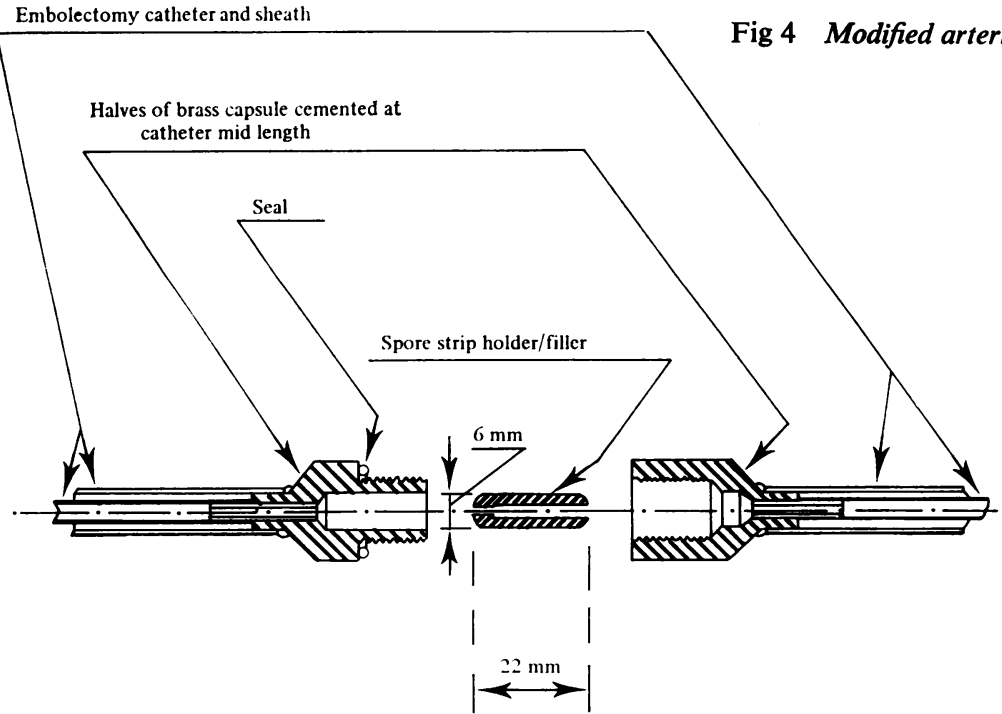

Fig 4 Modified arterial-embolectomy catheter 


\section{EXPERIMENTAL TEST CATHETER}

For the purposes of comparison the helix was tested in parallel with an object that was in routine use. An arterial embolectomy catheter, complete with sheath, was modified by the insertion of a spore capsule at its mid-length (fig 4). Before modification the length of the catheter was $78.5 \mathrm{~cm}(31 \mathrm{in}$.$) and$ its bore approximately $2 \mathrm{~mm}(1 / 13 \mathrm{in}$.). The capsule increased its length by $4.4 \mathrm{~cm}$ (1 3/4 in.). Plastic-tometal connexions were cemented with Araldite; the seal between the two halves of the catheter was completed by a compression ring.

The slotted cylindrical brass 'filler', which was a close drop-fit into the capsule, reduced the internal free space approximately to that of the normal catheter bore. Without the filler the catheter could have been considered abnormal because of the extra capsule volume at its central point. A spore strip was put in the slot of the filler which was then inserted into the male threaded half of the capsule. The other half of the capsule with its length of catheter was then screwed on firmly. The catheter, without wrapping, was placed horizontally in the sterilizer chamber with the test helix.

\section{Results}

With the standard steam-formaldehyde cycle (fig 1) we made 100 test runs at $80^{\circ} \mathrm{C}$ and 36 runs at $70^{\circ} \mathrm{C}$. Spores in the test helix were killed in all cases.

The next series of tests showed that it was more difficult to sterilize the test helix than the test catheter. As both objects were always sterilized by exposure to the complete cycle, it was necessary to produce a progressive reduction in the efficiency of the sterilizing system. A situation could be then reached in which spores were always killed in the test catheter but not in the helix. The simplest way of doing this was to decrease the number of pressure waves (fig 1) in the formalizing stage of the cycle, the other stages remaining the same. But with even only one pressure wave, spores were invariably killed in helix and catheter. When pressure waves

\begin{tabular}{|c|c|c|c|}
\hline \multirow[t]{2}{*}{ Test Organism } & \multirow[t]{2}{*}{ No. of Cycles } & \multicolumn{2}{|c|}{$\begin{array}{l}\text { No. of Tests Showing Growth of } \\
\text { Spores from }\end{array}$} \\
\hline & & Helix & Catheter \\
\hline $\begin{array}{l}\text { B. stearotherm- } \\
\text { ophilus }\end{array}$ & 12 & 11 & $\mathbf{0}$ \\
\hline B. pumilus & 15 & 12 & $\mathbf{0}$ \\
\hline Cl. sporogenes & 6 & 0 & $\mathbf{0}$ \\
\hline B. globigii & 10 & 9 & 0 \\
\hline
\end{tabular}

Table Comparison of effect on spores in test helix and catheter after exposure to formaldehyde cycle without pressure waves at $70^{\circ}-80^{\circ} \mathrm{C}$ were eliminated altogether, spores did sometimes survive in the helix but were always killed in the catheter (table).

\section{Discussion}

The range and complexity of articles now being presented for steam-formaldehyde sterilization makes the design of a test piece that will indicate the probable efficiency of the sterilizing process very difficult. Articles requiring treatment may vary from parts of ventilators or respirators to $x$-ray equipment, from nylon catheters to library books. The question of whether steam and gas can be relied upon to penetrate into screw threads, compression joints, and mechanical couplings of various kinds, etc, cannot be answered unequivocally. In general, long tubes of narrow bore, such as arterial or ureteric catheters, have always posed problems when formaldehyde is used as the sterilant. This is because formaldehyde cannot be relied upon to permeate certain plastic materials as does ethylene oxide; formaldehyde must be worked into the lumen of catheters and similar objects by a mechanical process of gas movement and diffusion through their open ends.

The very complexity of articles for sterilization, however, reduces the task of designing a test piece to that of practising the art of the possible. What can be done is to produce a test piece of known and definable difficulty; to show that in a given system it can be regularly and reliably sterilized and, by trial and error, to relate its sterilization to that of various articles.

Tubes such as catheters are ready-made test pieces but because of their narrow bore it is not easy to introduce bacteria or spores into them for testing purposes. Organisms are often used in liquid suspensions which are difficult to handle and prone to contamination during recovery and culture. Moreover, after these suspensions have been introduced the number of bacteria or spores remaining in the smooth and water-repellent lumen of catheters is most uncertain. Such procedures are clearly not practicable for everyday use-the more easily handled spore strip is preferable.

We have tried test pieces made of rubber or plastic tubing fitted with spore chambers but problems arising from plasticity, permeability, gas adsorption, and leakage have discouraged the use of these materials. Only non-permeable stainless-steel tubing with brazed or welded joints was satisfactory.

A typical catheter for low-temperature processing would be one similar to that modified and used in the comparative tests described here, ie, having a bore of about $2 \mathrm{~mm}$ with access at both ends, and a length of $78.5 \mathrm{~cm}$ (31 in.), giving a length-to-bore ratio 
of about 400:1. To define a tube simply in terms of such a ratio is arbitrary and is useful only when applied over a very limited range of bore diameters, from 1 to $5 \mathrm{~mm}$ or so. The internal volume of the tube, the roughness of its bore, and the speed at which pressure changes occur during sterilization will all influence the efficacy of air removal and gas penetration. Within the restricted range of dimensions discussed here, length-to-bore ratios provide a measure of a tube's probable resistance to a steamformaldehyde sterilizing process. For example, a tube and terminal capsule with a bore of $3 \mathrm{~mm}$ and a length of $230 \mathrm{~cm}$ (7ft. 6in.), ie, a length-to-bore ratio of $760: 1$, was easily and consistently sterilized with the formaldehyde system used here. A tube with a bore of $1 \mathrm{~mm}$ and a length of $152 \mathrm{~cm}(5 \mathrm{ft})$, a ratio of $1520: 1$, produced rather more resistance to the sterilizing process as judged by spore tests. Its behaviour was very similar to that of the test helix described here, which has a length-to-bore ratio of 1500:1.

Most of the tubes and catheters met in practice have access at both ends but the test helix is singleended to offer greater resistance to gas penetration. This feature also simplified loading of the spore capsule and made only one fixed joint necessary.

Requirements for a test piece are briefly as follows: (1) it must be made from permanent and non-permeable material; (2) the number of joints should be minimal and there must be no leakage at these points; (3) the use of spore strips must be possible; (4) the test piece must be at least as difficult to sterilize as other objects currently dealt with; (5) it must be easy to clean and dry; and (6) it must be convenient and easy to use.

Test pieces for formaldehyde so far described meet some but not all these requirements (Alder et a!, 1966; Gibson and Johnston, 1967; Dahlstrom, 1967; Gibson et al, 1968).

At present there is no reliable alternative to bacteriological control for the steam formaldehyde process. However, a colour-change-indicating system was used in many of our tests. White paper indicator strips were placed in the capsule of the test piece and in the control capsule, sometimes with the spore strips themselves. Formaldehyde produced a pink- $-\stackrel{0}{=}$ to-purple colouration of the strips. A colour change으 did not necessarily denote sterility but was useful in showing the extent of gas penetration. Colourindicating strips used during cycles without pressure waves showed that gas penetrated the catheter very을. well, but very little penetrated the helix. So far, only $\frac{\bar{c}}{\frac{5}{5}}$ a very rough correlation between gas concentration,,$\stackrel{\Omega}{\Omega}$ time of exposure, temperature, and density of colour change has been attempted. Refinement of the method so that it can eventually be used as a reliable. substitute for bacteriological control would have $\vec{\omega}$ obvious advantages.

The test helix has so far been used only with the steam-formaldehyde system. There seems to be noi reason why it should not be used for the control of 0 other gas-sterilization methods.

We thank Dr R. Blowers for his help in the pre-을 paration of the paper and for laboratory facilities ; $\vec{c}$ Dr J. C. Kelsey for his advice and encouragement; $\mathbb{\infty}$ Dr Joan Gardner for her interest and for suggesting the use of B. pumilus in the tests; Miss B. L. Simmons for use of the sterilizer and for her ready cooperation; $;$ and Mr R. Perera, of the British Sterilizer Co Ltd, $\frac{\vec{c}}{\varphi}$ for making the tests pieces and modifying t\&e sterilizer.

\section{References}

Alder, V. G., Brown, A. M., and Gillespie, W. A. (1966). Dis: $n-0$ fection of heat-sensitive material by low-temperature steam and음 formaldehyde. J. clin. Path., 19, 83-89.

Alder, V. G., Gingell, J. C., and Mitchell, J. P. (1971). Disinfection of cystoscopes by subatmospheric steam and steam and fcrma!d-o ehyde at $80^{\circ}$ C. Brit. med. J., 3, 677-680.

Bowie, J. H., Kelsey, J. C., and Thompson, G. R. (1963). The Bowie and Dick autoclave tape test. Lancet, 1, 586-587.

Dahlstrom, H. (1967). Disinfection by low-temperature steam. Brit Hosp. J. and soc. Serv. Rev., 77, 1215-1217.

Gibson, G. L., and Johnston, H. P. (1967). Practical sterilization by low-temperature steam with formaldehyde. Brit. Hosp. J. soc Serv. Rev., 77, 1208-1215.

Gibson, G. L., Johnston, H. P., and Turkington, V. E. (1968)

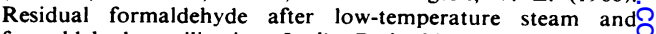
formaldehyde sterilization. J. clin. Path., 21, 771-775.

Kelsey, J. C. (1967). Use of gaseous antimicrobial agents with special reference to ethylene oxide. J. appl. Bact.. 30, 92-100.

Mitchell, J. P., and Alder, V. G. (1970). Recent developments on the use of subatmospheric steam and formaldehyde gas at $80 \mathrm{C}$ for the disinfection of cystoscopes. Brit. Hesp.J. soc. Serv. Rev., 80. ․ㅡ.
1944-1946. 